\title{
After-effects of Tsunami on distribution and abundance of mosquitoes in rice-field areas in Miyagi Prefecture, Japan in 2011
}

\author{
Yoshio Tsuda ${ }^{*, 1)}$, Michio Haseyama ${ }^{2)}$, Keiichi Ishida ${ }^{3)}$, Jun Nirzuma ${ }^{4)}$, Kyeong Soon Kim ${ }^{1)}$, \\ Daiki Yanagi ${ }^{2)}$, Nozomi Watanabe ${ }^{2)}$ and Mutsuo KobaYashi ${ }^{1)}$ \\ * Corresponding author: Department of Medical Entomology, National Institute of Infectious Diseases, \\ Toyama 1-23-1, Shinjuku-ku, Tokyo, 162-8640 Japan \\ ${ }^{1)}$ Department of Medical Entomology, National Institute of Infectious Diseases, \\ Toyama 1-23-1, Shinjuku-ku, Tokyo, 162-8640 Japan \\ 2) Narita Airport Quarantine Station, Aza-Furugome 1-1, Furugome, Narita, Chiba, 282-0004 Japan \\ 3) Sendai Quarantine Station, Teizandori 3-4-1, Shiogama, Miyagi, 985-0011 Japan \\ 4) Tokyo Quarantine Station, Aomi 2-7-11, Koto-ku, Tokyo, 135-0064 Japan
}

(Received: 22 December 2011; Accepted: 23 January 2012)

\begin{abstract}
The Tsunami caused by the Great East Japan Earthquake on 11 March 2011 in north-eastern Japan destroyed urban and rural environments completely, including buildings, dwellings, roads, bridges, agricultural fields and natural vegetation. The after-effects of the Tsunami on the distribution and abundance of mosquitoes were studied in rice field areas in Miyagi Prefecture, Japan during June to August 2011. Adult mosquitoes were collected by traps enhanced with $1 \mathrm{~kg}$ dry ice and the density was compared between the "Tsunani" area and "No Tsunami" area. A total of 6,542 adults of 9 species in 4 genera were collected and the following 4 species were dominant: Culex pipiens pallens, Cx. inatomii, Cx. tritaeniorhynchus and Aedes albopictus. The high density and expanded distribution of Cx. inatomii was marked. The adult density of the former 3 dominant species was significantly higher in the Tsunami area than No Tsunami area, while Ae. albopictus was significantly abundant in the No Tsunami area. Ground pools in disaster areas contained brackish water with 0.47 and $0.21 \%$ average salinity in June and August 2011, respectively. The percentage of water samples with mosquito larvae increased from $2.7 \%$ in June to $79.5 \%$ in August, suggesting the expansion of the larval distribution of $C x$. inatomii and $C x$. tritaeniorhynchus as well as Anopheles sinensis-group.
\end{abstract}

Key words: Tsunami, earthquake, north eastern Japan, mosquitoes, Culex inatomii

\section{INTRODUCTION}

The disaster caused by the Great East Japan Earthquake and Tsunami on 11 March 2011 in north-eastern Japan was serious, and human dwellings, buildings, roads, bridges and agricultural fields as well as natural vegetation were destroyed completely both in urban and rural areas. Because of the shortage of energy and manpower, most activities to recover from the damage have been concentrated in urban areas. The recovery of destroyed agricultural fields has progressed slowly and most of the destroyed fields in ru- ral areas have been remained as they are.

The main disaster area is roughly divided into two geographically different areas: hilly areas with a deeply indented coastline that are located mainly in Iwate Prefecture and northern Miyagi Prefecture; flat areas with a smooth coastline that are located from southern Miyagi Prefecture to Fukushima Prefecture. The flat areas are used for rice plantation and rice paddies are distributed widely. Rice fields are the major larval habitats of mosquitoes of medical importance in Japan, such as Culex tritaeniorhynchus Giles, Anopheles sinensis Wiedemann and Aedes vexans nipponii 
(Theobald). Kamimura (1968) collected 17, 24, and 25 mosquito species in Iwate, Miyagi and Fukushima Prefecture, respectively, in the 1960s. Regarding rice field mosquitoes in Miyagi Prefecture, Kato et al. (1967) conducted detailed studies on the seasonal abundance of mosquitoes in cow sheds located in 14 study areas and the following 5 mosquito species were dominant in 1965, An. sinensis, $C x$. tritaeniorhynchus, Ae. vexans nipponii, Armigeres subalbatus (Coquillett), Cx. pipiens pallens Coquillett. No data are available regarding the recent mosquito situation in disaster areas.

The destruction of the environment by the earthquake and Tsunami is so complete and the disaster area is so wide that the recovery of populations of wild animals and plants will progress gradually each year. This is an important opportunity not only scientifically but also practically to apply ecological theo- ries and predict the recovery process of wild populations. We selected rice field areas in Miyagi Prefecture for mosquito surveys in this study to clarify the dominant species and elucidate the after-effects of a Tsunami on the distribution and abundance of mosquitoes in disaster areas.

\section{Materials ANd Methods}

Study area: The disaster area is roughly divided into two areas based on the geographical features; hilly areas with a deeply indented coastline and flat areas with a smooth coastline. We examined the flat areas where rice plants were cultivated widely located in the southern part of Miyagi Prefecture, Japan (Fig. 1). A huge Tsunami, caused by the earthquake on 11 March 2011, reached regions 5 to $6 \mathrm{~km}$ from the seashore. Almost all human dwellings and buildings along the seashore were completely destroyed and

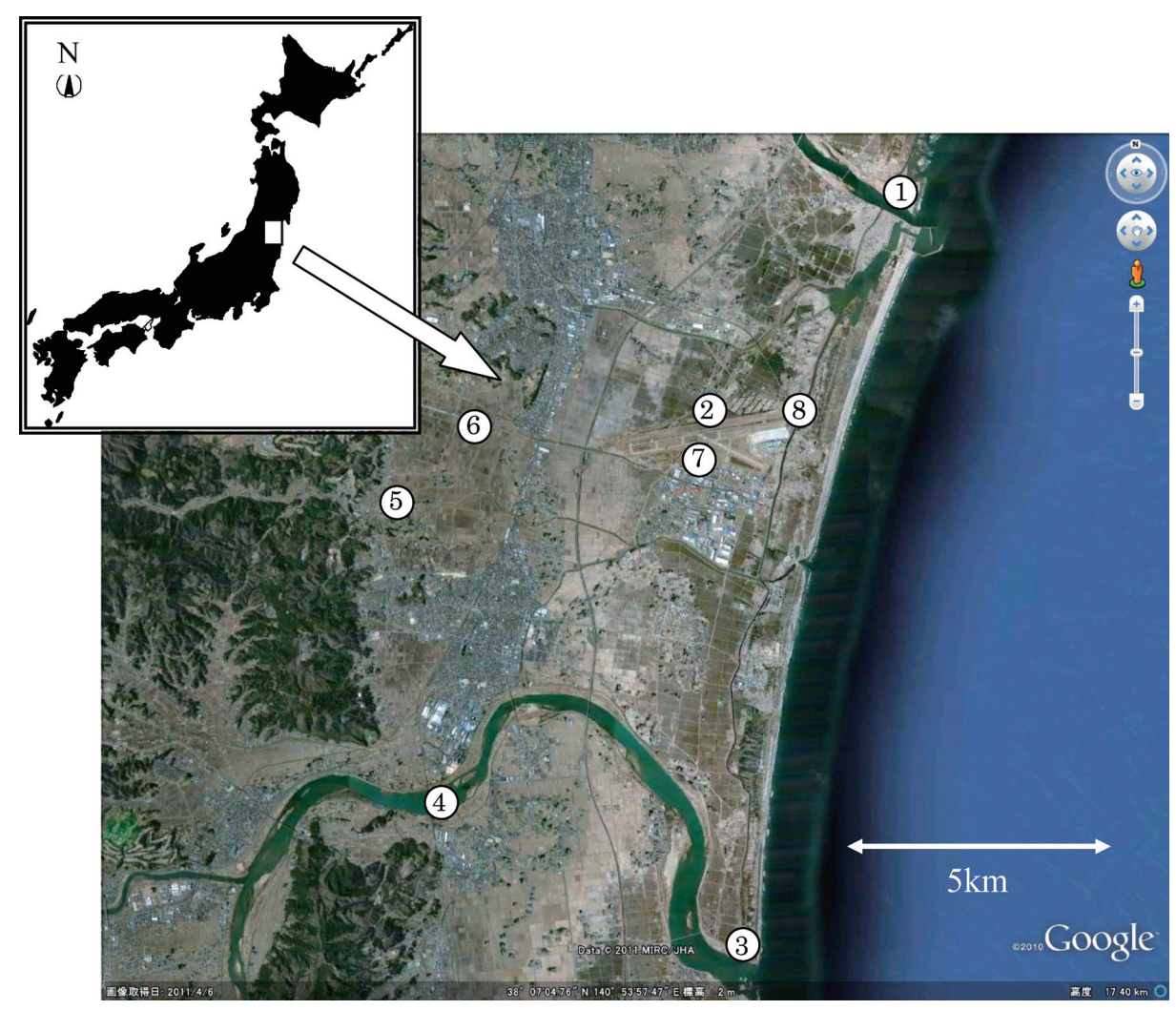

Fig. 1. Locations of 8 sites for adult mosquito collections in rice-field areas in Miyagi Prefecture, Japan. Two $\mathrm{CO}_{2}-$ baited traps were placed at approximately $10 \mathrm{~m}$ distance at each site. See Table 1 for details. 
washed away. In rice field areas, agricultural fields were flooded with seawater and damaged heavily by debris carried by the Tsuna$\mathrm{mi}$. There were many ground pools of various sizes containing brackish water (Fig. 2).

Within the study area we could easily distinguish two areas, either damaged or undamaged by the Tsunami, and the boundary was about 5 to $6 \mathrm{~km}$ from the seashore. Mosquito surveys were conducted in both the damaged "Tsunami" area, and undamaged "No Tsunami" area to compare the distribution and abundance of mosquitoes.

Mosquito survey: Mosquito surveys were carried out monthly from June to August 2011. Both adult and larval collections were conducted. For adult collections, 10 CDClike traps without a bulb baited with $1 \mathrm{~kg}$ dry ice were used and operated continuously for
3 days. Mosquitoes in the traps were collected every morning and taken to Sendai Quarantine Station for species identification. Mosquito species was identified following the morphological keys by Tanaka et al. (1979). For the identification of $C x$. pipiens groups, the PCR-based method developed by Kasai et al. (2008) was used, and 28 adults collected in June, July and August 2011 were identified. Since all the specimens were identified as $C x$. pipiens pallens, the remaining samples were treated as $C x$. pipiens pallens in this paper. Five trap sites (1 to 5 in Fig. 1) were selected, and 2 traps each were placed and operated for 3, 2 and 1 day(s) in June, July and August 2011, respectively. In July and August, the trap sites were selected along a transect from the seashore to inland $(2,5,6,7$ and 8 in Fig. 1) and adult collections were conducted by using 2 traps each for 1 and 2 days, respec-
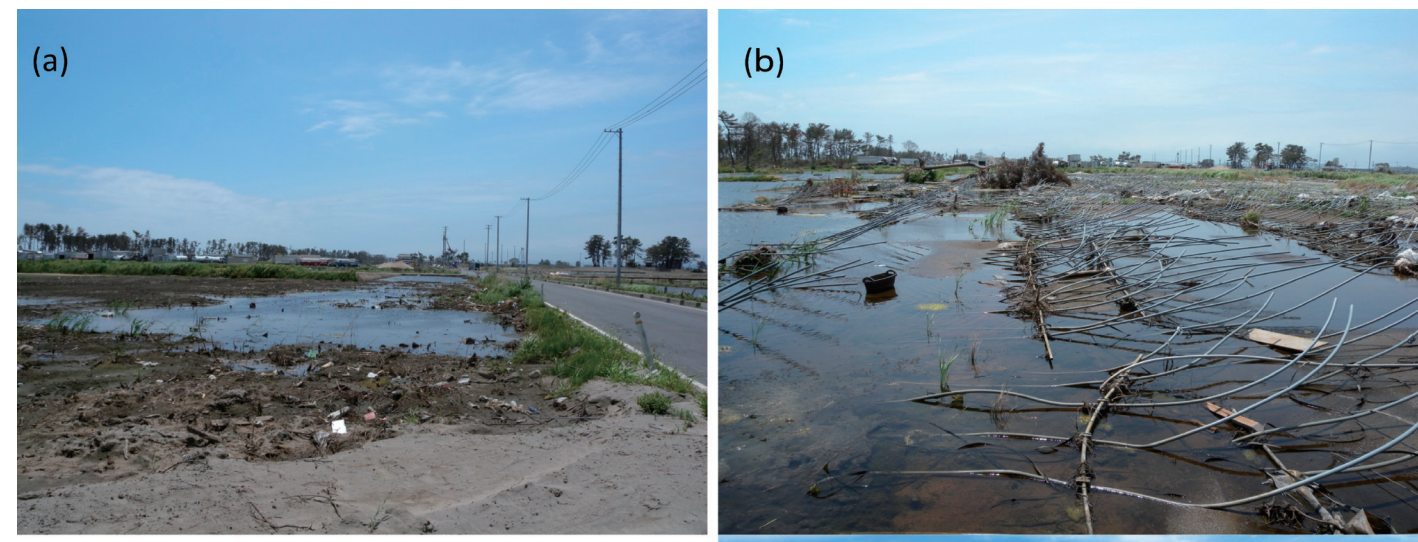

(c)

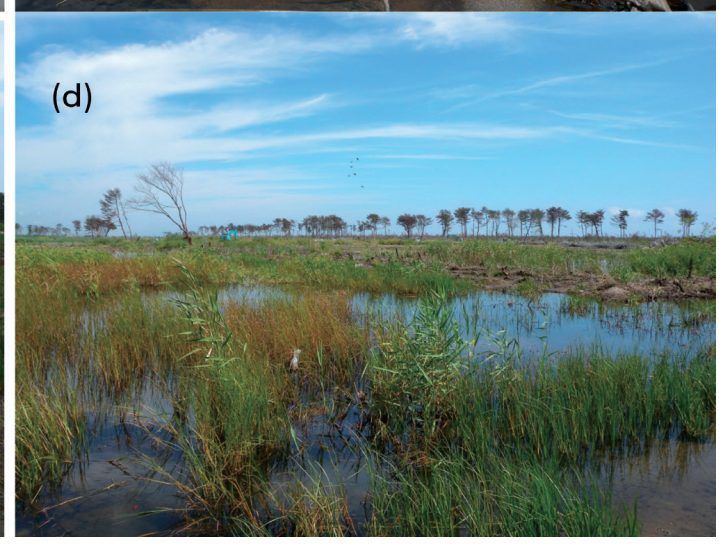

Fig. 2. (a) A ground pool in a depression along the roadside on 21 July 2011, (b) a ground pool in a destroyed green house, on 21 July 2011, (c) rice fields with brackish water on 14 June 2011, (d) grasses grew in rice fields on 30 August 2011 and ground pools became suitable larval habitats for $C x$. inatomii and $C x$. tritaeniorhynchus. 
Table 1. Location and environmental conditions of mosquito-trap sites in rice-field areas of Miyagi Prefecture, Japan.

\begin{tabular}{llcl}
\hline \hline Location & $\begin{array}{c}\text { Distance from } \\
\text { seashore, } \mathrm{km}\end{array}$ & \multicolumn{1}{c}{ Environmental conditions } \\
\hline 1 & N38.10.56, E140.57.23 & 0.5 & Tsunami area, river mouth of Natori river \\
2 & N38.8.31.896, E140.54.53.886 & 2.6 & Tsunami area, north of Sendai airport \\
3 & N38.3.8.115, E140.55.7.153 & 0.25 & Tsunami area, river mouth of Abukuma river \\
4 & N38.5.33, E140.52.15 & 5.0 & No Tsunami area, riverside bush along Abukuma river \\
5 & N38.8.7.624, E140.50.45.284 & 8.3 & No Tsunami area, beside a rural house \\
6 & N38.8.36.73, E140.51.54.91 & 6.2 & No Tsunami area, center of a rice-field area \\
7 & N38.8.31.267 E140.54.51.279 & 2.5 & Tsunami area, south of Sendai airport \\
8 & N38.9.5 E140.56.29 & 0.9 & Tsunami area, east of Sendai airport \\
\hline
\end{tabular}

tively, to show the different spatial distribution of host-seeking females among mosquito species. The location and environmental conditions of the trap sites are listed in Table 1.

Collection sites of larvae were selected from both the Tsunami area and No Tsunami area. Rice paddies with growing rice plants in the No Tsunami area were examined by a dipper $(10 \mathrm{~cm}$ diameter and $350 \mathrm{ml})$ and 38 , 12 and 9 samples consisting of 5 to 10 dips of water were collected in June, July and August 2011. A total of 37, 26 and 35 larval samples were collected from ground pools found in the Tsunami area in June, July and August 2011, respectively. Salinity of the collected water was measured by a digital salinity meter (SS-31A; Sekisui) and recorded in the fields. Larvae were killed and kept in alcohol for later identification. Larvae of Anopheles sinensis Wiedemann, An. sineroides Yamada, and $\mathrm{An}$. lesteri Baisas and $\mathrm{Hu}$ are almost indistinguishable (Tanaka et al., 1979) and most of our larval samples included young instars, therefore these Anopheles larvae were treated as Anopheles sinensis-group (Tanaka, 2005).

Blood-meal identification: Seven and one blood fed-females of $C x$. pipiens group and $C x$. inatomii Kamimura and Wada, respectively, were collected by dry-ice traps and blood-meal identification was carried out following Kim et al. (2009a).

Statistical analysis: Average number of females/trap/day was calculated for dominant mosquito species and compared between Tsunami and No Tsunami areas. The significance of the observed difference in mosquito density was tested by t-test by applying log (1 $+n)$ transformation. To describe the spatial distribution of host-seeking females along a transect from the seashore to inland, the relationships between the distance from seashore and average numbers of females/trap/day were analyzed by exponential curve fitting.

\section{RESUlTS}

Total of 6,542 adult mosquitoes of 9 species in 4 genera were collected during the study period (Table 2). A large number of Culex inatomii were collected as well as $C x$. pipiens pallens, $C x$. tritaeniorhynchus and Aedes albopictus (Skuse). The remaining 6 species, Armigeres subalbatus, Cx. orientalis Edwards, An. sinensis, Cx. bitaeniorhynchus Giles and Ae. vexans nipponii, were collected in small numbers, less than 10 in total.

Statistically significant differences in the average number of females were found between Tsunami and No Tsunami areas for 4 dominant species in July and August 2011 (Table 3). Density of $C x$. pipiens pallens, $C x$. inatomii and $C x$. tritaeniorhynchus in the Tsunami area was significantly higher than in the No Tsunami area, while the opposite result was found for Ae. albopictus, which showed higher density in the No Tsunami area than Tsunami area.

The spatial distributions of dominant species are shown in Fig. 3. The exponential curve was fitted well to the relationship be- 
Table 2. Results of dry-ice trap collections conducted in Tsunami and No Tsunami areas in rice-field areas in Miyagi Prefecture, Japan during June to August 2011.

\begin{tabular}{|c|c|c|c|c|c|c|c|c|}
\hline \multirow[b]{2}{*}{ Species } & \multicolumn{4}{|c|}{ No Tsunami area } & \multicolumn{4}{|c|}{ Tsunami area } \\
\hline & $\begin{array}{l}\text { June } \\
(8)\end{array}$ & $\begin{array}{l}\text { July } \\
\text { (12) }\end{array}$ & $\begin{array}{c}\text { August } \\
\text { (12) }\end{array}$ & $\begin{array}{l}\text { Total } \\
(32)\end{array}$ & $\begin{array}{l}\text { June } \\
(12)\end{array}$ & $\begin{array}{l}\text { July } \\
\text { (18) }\end{array}$ & $\begin{array}{c}\text { August } \\
\text { (18) }\end{array}$ & $\begin{array}{l}\text { Total } \\
(48)\end{array}$ \\
\hline Cx. pipiens pallens & 1 & 194 & 133 & 328 & 10 & 2,565 & 1,415 & 3,990 \\
\hline Cx. inatomii & 0 & 1 & 1 & 2 & 7 & 248 & 1,230 & 1,485 \\
\hline Cx. tritaeniorhynchus & 0 & 11 & 86 & 97 & 0 & 86 & 961 & 1,047 \\
\hline Ae. albopictus & 2 & 35 & 249 & 286 & 0 & 1 & 14 & 15 \\
\hline Ar. subalbatus & 0 & 1 & 4 & 5 & 0 & 0 & 1 & 1 \\
\hline$C x$. orientalis & 0 & 0 & 2 & 2 & 2 & 0 & 0 & 2 \\
\hline An. sinensis & 0 & 1 & 0 & 1 & 0 & 2 & 0 & 2 \\
\hline Cx. bitaeniorhynchus & 0 & 0 & 1 & 1 & 0 & 0 & 0 & 0 \\
\hline Ae. vexans nipponii & 1 & 0 & 0 & 1 & 0 & 0 & 0 & 0 \\
\hline Total & 4 & 243 & 476 & 723 & 19 & 2,902 & 3,621 & 6,542 \\
\hline
\end{tabular}

Number in parentheses shows the total number of trap nights.

Table 3. Comparisons of adult densities (females/trap/day) of four dominant mosquitoes between Tsunami and No Tsunami areas in Miyagi Prefecture, Japan in July and August 2011.

\begin{tabular}{|c|c|c|c|c|c|c|}
\hline & \multicolumn{3}{|c|}{ July } & \multicolumn{3}{|c|}{ August } \\
\hline & No Tsunami & Tsunami & $p^{*}$ & No Tsunami & Tsunami & $p$ \\
\hline Cx. pipiens pallens & $22.8 \pm 6.9$ & $210.9 \pm 69.1$ & 0.005 & $11.3 \pm 13.5$ & $78.5 \pm 65.6$ & 0.012 \\
\hline Cx. inatomii & $0.1 \pm 0.4$ & $20.5 \pm 15.4$ & $<0.001$ & $0.1 \pm 0.3$ & $68.3 \pm 60.6$ & $<0.001$ \\
\hline Cx. tritaeniorhynchus & $1.3 \pm 1.0$ & $7.2 \pm 5.2$ & $<0.001$ & $7.2 \pm 10.5$ & $53.4 \pm 97.2$ & $<0.001$ \\
\hline Ae. albopictus & $4.3 \pm 8.3$ & $0.1 \pm 0.3$ & 0.029 & $21.3 \pm 42.6$ & $0.2 \pm 0.5$ & 0.010 \\
\hline
\end{tabular}

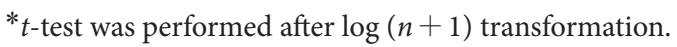

tween the distance from the seashore and the density of females of $C x$. pipiens pallens, $C x$. inatomii and Ae. albopictus, with coefficients of determination of $0.836,0.847$ and 0.789 , respectively. Based on the exponential curves, the density of host-seeking mosquitoes at the boundary between Tsunami and No Tsunami areas was estimated as 26, 1.7 and 1.5 for $C x$. pipiens pallens, $C x$. inatomii and Ae. albopictus, respectively. The spatial distribution of $C x$. tritaeniorhynchus showed no clear tendency along the transect from the seashore to inland.

Seven blood-fed Cx. pipiens pallens, 5 in July and 2 in August, and 1 blood-fed Cx. inatomii in August were collected by dry-ice traps during the study period. The blood source animals were identified as Parus major for 5 blood-fed Cx. pipiens pallens and Rattus norvegicus for $C x$. inatomii. The remaining 2 samples showed no amplification.

The results of larval surveys are summarized in Table 4 . The percentage of water samples containing mosquito larvae was low $(2.7 \%)$ in June, increased to $31.6 \%$ in July and reached $79.5 \%$ in August 2011. The results suggested the expansion of the larval distribution of $C x$. inatomii, $C x$. tritaeniorhynchus and $A n$. sinensis-group during the study period. Although a high adult density of Cx. pipiens pallens was observed, their larvae were collected in only 3 samples in August 2011. The density of larvae (number of larvae/dip) observed in August varied from 0.01 to 1.5 depending on species; the average larval density of Cx. inatomii, Cx. tritaeniorhynchus, $C x$. pipiens pallens, Cx. orientalis, An. sinensis-group was $1.5,0.9,0.5,0.02$, and 0.01 , respectively.

The salinity of collected water ranged be- 

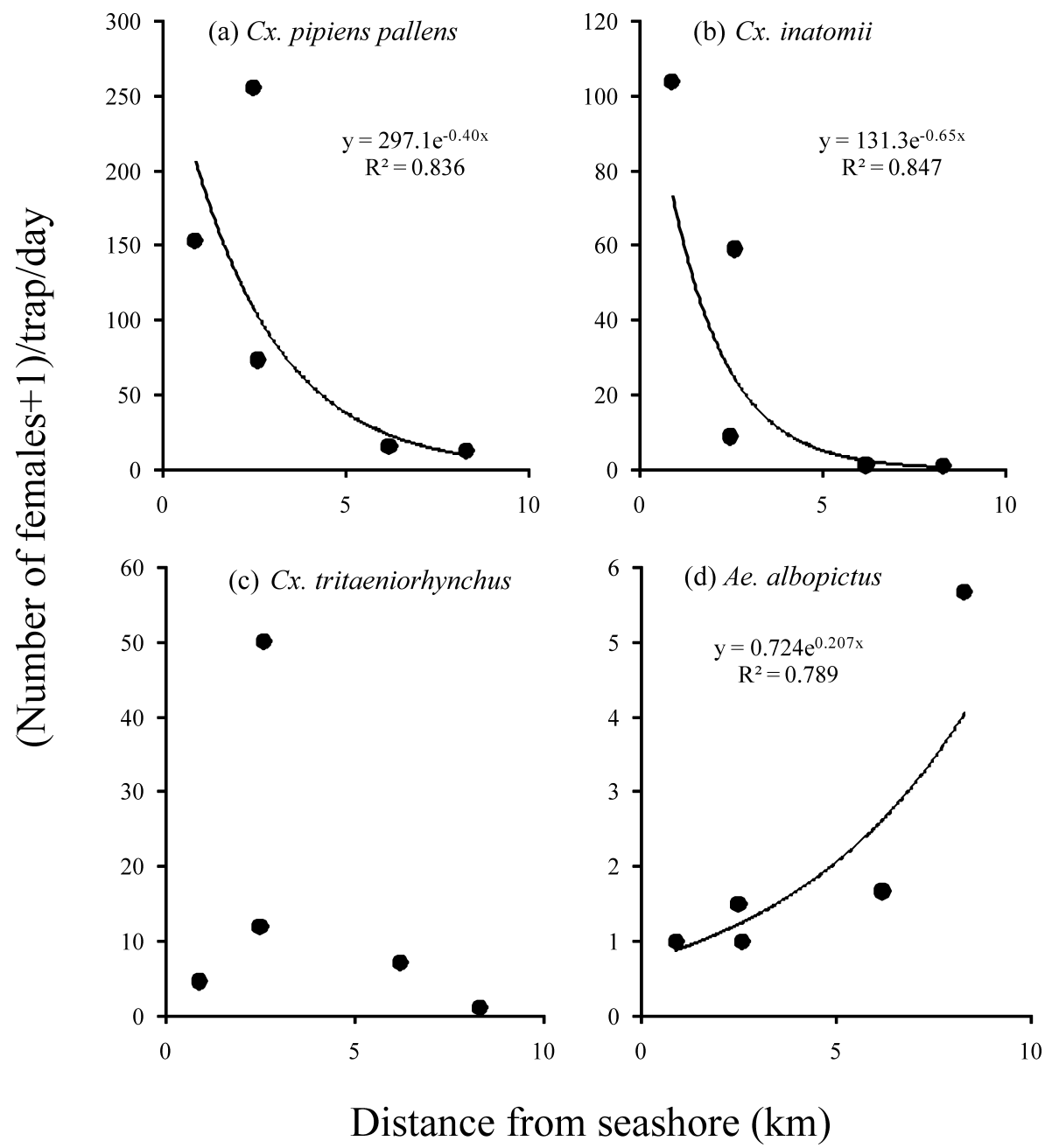

Fig. 3. Relationship between the distance from the seashore and the density of females $(1+n /$ trap/day $)$ for four dominant species observed in Miyagi Prefecture, Japan in 2011.Exponential curve fitting was performed.

tween 0 to $0.9 \%$. The average salinity of sampled water was calculated as $0.47 \pm 0.21 \%$, $0.27 \pm 0.15 \%$ and $0.21 \pm 0.19 \%$ in June, July and August 2011, respectively. No mosquito larvae were collected from ground pools of 0.8 and $0.9 \%$ salinity. Average salinity of water where mosquito larvae were collected was calculated for each mosquito species in Table 5 . The average salinity ranged between 0 and 0.33 , and differences in average salinity among mosquito species were not statistically significant $(F=0.289, p=0.755$ in July and $F=2.024, p=0.111$ in August 2011, ANOVA).

\section{Discussion}

The present study clearly showed the aftereffects of the Tsunami on mosquito distribution and abundance in the disaster areas. The high density and expanding distribution of $C x$. inatomii was marked. Culex inatomii had been collected from a few locations in Japan before 2000, such as Okayama and Osaka (Kamimura and Wada, 1974; Mizuta et al., 1999); however, a recent entomological study found this species inhabiting Tokyo bay, Sakata wetlands in Niigata, and Kushiro (Tsuda et al., 2009; Kim et al., 2009b; Katano et al., 2010; Ejiri et al., 2011). A wide geo- 
Table 4. Mosquito species found in the larval surveys and the number of samples with larvae collected from rice paddies and ground pools in Miyagi Prefecture, Japan from June to August 2011.

\begin{tabular}{lccc}
\hline \hline \multicolumn{1}{c}{ Species } & June & July & August \\
\hline Cx. inatomii & 0 & 2 & 21 \\
Cx. tritaeniorhynchus & 0 & 7 & 10 \\
An. sinensis-group & 1 & 4 & 5 \\
Cx. orientalis & 1 & 0 & 4 \\
Cx. pseudovishnui & 1 & 0 & 0 \\
Cx. pipiens pallens & 0 & 0 & 3 \\
Number of samples with mosquito larvae (\%) & $2(2.7)$ & $12(31.6)$ & $35(79.5)$ \\
Total number of samples & 75 & 38 & 44 \\
\hline
\end{tabular}

Table 5. Average salinity $(\% \pm \mathrm{SD})$ of water where larvae were collected in Miyagi Prefecture, Japan during June to August 2011.

\begin{tabular}{lccc}
\hline \hline & June & July & August \\
\hline An. sinensis-group & 0.2 & $0.33 \pm 0.05$ & $0.06 \pm 0.05$ \\
Cx. inatomii & - & $0.25 \pm 0.21$ & $0.14 \pm 0.19$ \\
Cx. tritaeniorhynchus & - & $0.31 \pm 0.12$ & $0.2 \pm 0.13$ \\
Cx. pipiens pallens & - & - & $0.1 \pm 0.1$ \\
Cx. orientalis & 0 & - & 0 \\
Cx. pseudovishnui & 0 & - & - \\
\hline
\end{tabular}

Differences in average salinity among mosquito species were not statistically significant $(F=0.289, p=.755$ in July and $F=2.024, p=0.111$ in August).

graphic distribution of $C x$. inatomii is also suggested from the results of mosquito surveys conducted by the Quarantine Station in Japan (Mizuta et al., 2012). Furthermore, the distribution of $C x$. inatomii outside Japan was reported in Korea and China (Ree, 1998; Xu et al., 1993); therefore, Cx. inatomii has a wider geographic distribution than previously expected. Although the distribution of $C x$. inatomii has not been reported in Miyagi Prefecture, the lack of collection records may be because of few mosquito studies conducted in the current study area in the past. Small populations of $C x$. inatomii have probably been maintained in temporal ground pools appearing beside the seashore in Miyagi Prefecture, and they were the source populations of the outbreak observed in this study. The ground pools widely present in the Tsunami area provided good larval habitats for $C x$. inatomii and resulted in the density increase and the expansion of spatial distribution, because $C x$. inatomii larvae develop well in brackish water and adults reproduce autogenously
(Katano et al., 2010).

As shown in Fig. 3, the spatial distribution of host-seeking $C x$. inatomii was restricted to near the larval habitats. One of the species related to $C x$. inatomii occurring in the Mediterranean area, $C x$. modestus Ficalbi, has similar ecology to $C x$. inatomii and its flight range is considered to be 500 to $700 \mathrm{~m}$ (Pradel et al., 2009; Cailly et al., 2011; Becker et al., 2010). Therefore, the flight range of $C x$. inatomii seems to be the same as $C x$. modestus, and a low chance of contact with humans is expected at present, because temporary dwellings are constructed in hilly areas far away from the larval habitats of $C x$. inatomii. The blood meal of blood-fed $C x$. inatomii in this study was identified as $R$. norvegicus, indicating contact with wild animals.

The reason for the high density of $C x$. pipiens pallens in the Tsunami area is unclear at present. When the Tsunami destroyed the study area, adults of $C x$. pipiens pallens were still in diapause, because the cumulative average temperature from the beginning of the 
year to 8 March 2011 in Sendai, Miyagi was 123.4, quite lower than the value suggested for the appearance of overwintered Cx. pipiens pipiens in the USA, 400 degree days (Bolling et al., 2007; Ciota et al., 2011). There are no available data on the appearance day of overwintered Cx. pipien pallens in Miyagi Prefecture. During the course of sweeping collections of overwintered Cx. tritaeniorhynchus in Tokyo (Tsuda and Kim, 2010), some overwintered females of $C x$. pipiens pallens were found in the sweeping samples and were available for estimation of the appearance day of $C x$. pipiens pallens in Tokyo as a reference. The first overwintered female of $C x$. pipiens pallens was collected on 16 March in 2008, 7 March in 2009 and 5 March in 2010 and the cumulative average temperature from the beginning of the year was 502, 479.8 and 442.5 degree days, respectively. The cumulative degree days in Sendai, Miyagi Prefecture this year reached 400 degree days at the end of April; thus, it is likely that $C x$. pipiens pallens were still in diapauses and overwintering when the Tsunami disaster occurred in Miyagi Prefecture on 11 March 2011. It is known that overwintering $C x$. pipiens pallens can be found in caves and/or cellars (Hayashi et al., 1965; Shimogama and Takatsuki, 1967; Makiya and Sakurai, 1975); therefore, Culex pipiens pallens in these overwintering sites situated outside of the Tsunami area were able to escape the disaster and successfully overwintered and appeared at the end of April 2011. The drainage systems around human dwellings and irrigation cannels in rice field areas were destroyed by the earthquake and Tsuna$\mathrm{mi}$, and various water bodies of different sizes formed on the ground. Some of these water bodies were good larval habitats for Cx. pipiens pallens and produced a large number of adults observed in July and August 2011, although we found $C x$. pipiens pallens larvae in only $2 \%(3 / 157)$ of larval samples. Nearly all ground pools in the Tsunami area examined in this study contained brackish water and this result partly explains the small number of larvae of $C x$. pipiens pallens collected at our study site.

A high occurrence of Cx. tritaeniorhynchus larvae in brackish ground pools was found in this study. The result indicates that $C x$. tritaeniorhynchus larvae are capable of developing in brackish water. Since no studies have been carried out on the effects of the salinity of rearing water on the development and survival of larvae of Cx. tritaeniorhynchus, laboratory studies will be required to evaluate the after-effects of the Tsunami on the adult density of $C x$. tritaeniorhynchus in the future.

The adult density of Ae. albopictus was significantly lower in the Tsunami area than in the No Tsumani area, indicating the destructive effects of the Tsunami on larval habitats of Ae. albopictus, which are located mainly beside human dwellings, such as in water catchments, earthenware pots, stone vases, used tires, bamboo stumps etc. These larval habitats were destroyed and flushed out by the sea wave; therefore, Ae. albopictus populations persisting in the No Tsunami area are considered to be the source population. The dispersal or flight ability of insects is an important ecological character determining their colonizing ability. The flight range of $A e$. albopictus is usually short, less than $100 \mathrm{~m}$ (Hawley, 1988), indicating the low colonizing ability of Ae. albopictus in the disaster areas, and thus, only a small number of adult Ae. albopictus succeeded in immigrating into the disaster area during the summer season. Some of the immigrated Ae. albopictus will become source populations next year and density increase and expansion of the spatial distribution is expected because the potential larval habitats of Ae. albopictus are abundant in the disaster areas. Continuous adult mosquito surveillance in next season will be necessary to confirm the colonization and re-establishment of Ae. albopictus in disaster areas with human activities.

The habitat destruction of Ae. vexans nipponii was also suggested in the present study. Although only one female Ae. vexans nipponii was collected in this study, Kato et al. (1967) reported Ae. vexans nipponii as one of the dominant mosquitoes in rice field areas in Miyagi Prefecture in 1965. This species overwinters as eggs and the overwintering eggs are laid in soil; therefore, it is likely that eggs 
laid in rice fields were flushed out by the Tsunami and the density of the overwintered generation decreased greatly this year.

\section{ACKNOWLEDGEMENTS}

We thank the staff of Sendai Quarantine Station for their help with field mosquito collections and laboratory work. Our thanks are also due to Narita Airport Quarantine Station and Tokyo Quarantine Station for their collaboration in field studies with the Department of Medical Entomology, National Institute of Infectious Diseases. This study was partially supported by a Grant-in Aid for Scientific Research on Emerging and Re-emerging Infectious Diseases from The Ministry of Health, Labour and Welfare (H21-Shinko-Ippan-005) and the Environment Research and Technology Development Fund (S-8) of the Ministry of the Environment, Japan.

\section{REFERENCES}

Becker, N., Petric, D., Zgomba, M., Boase, C., Madon, M., Dahl, C. and Kaiser, A. 2010. Mosquitoes and Their Control. 2nd ed., 577 p., Springer, London.

Bolling, B. G., Moore, C. G., Anderson, S. L., Blair, C. D. and Beaty, B. J. 2007. Entomological studies along the Colorado front range during a period of intense West Nile virus activity. J. Am. Mosq. Control Assoc., 23: 3746.

Cailly, P., Balenghien, T., Ezanno, P., Fontenille, D., Toty, C. and Tran, A. 2011. Role of the repartition of wetland breeding sites on the spatial distribution of Anopheles and Culex, human disease vectors in Southern France. Parasit. Vect., 4: 65.

Ciota, A. T., Drummond, C. L., Drobnack, J., Ruby, M. A., Kramer, L. D. and Ebel, G. D. 2011. Emergence of Culex pipiens from overwintering hibernacula. J. Am. Mosq. Control Assoc., 27: 21-29.

Ejiri, H., Sato, Y., Kim, K.S., Hara, T., Tsuda, Y., Imura, T., Murata, K. and Yukawa, M. 2011. Entomological study on transmission of the avian malaria parasite in a zoological garden in Japan: Blood-meal identification and detection of avian malaria parasite DNA from bloodfed mosquitoes. J. Med. Entomol., 48: 600-607.

Hayashi, S., Kurihara, T. and Saito, K. 1965. Studies on the age of mosquitoes IV. The seasonal fluctuation of age composition and density of field population of Culex pipiens pallens. Jpn. J. Sant. Zool., 16: 110-117. (in Japanese with English summary)

Hawley, W. A. 1988. The biology of Aedes albopictus. J. Am. Mosq. Cotrol Assoc., Suppl., 1: 1-40.

Kamimura, K. 1968. The distribution and habit of medi- cally important mosquitoes of Japan. Jpn. J. Sanit. Zool., 19: 15-34. (in Japanese with English summary)

Kamimura, K. and Wada, Y. 1974. A new subspecies of Culex (Barraudius) modestus from Japan. (Diptera: $\mathrm{Cu}-$ licidae). Jpn. J. Sanit. Zool., 25: 13-20.

Kasai, S., Komagata, O., Tomita, T., Sawabe, K., Tsuda, Y., Kurahashi, H., Ishikawa, T., Motoki, M., Takahashi, T., Tanikawa, T., Yoshida, M., Shinjo, G., Hashimoto, T., Higa, Y. and Kobayashi, M. 2008. PCR-based identification of Culex pipiens complex collected in Japan. Jpn. J. Infect. Dis., 61: 184-191.

Katano, R., Tsuda, Y., Saitoh, Y. and Kobayashi, M. 2010. Experimental studies on the ecology of Culex inatomii (Diptera: Culicidae): effects of salinity and temperature on larval development and reproduction of populations during the cool season. Med. Entomol. Zool., 61: 327-333. (in Japanese with English abstract)

Kato, M., Yajima, T. and Ishii, T. 1967. Seasonal abundance of mosquitoes collected by animal baited traps in Miyagi Prefecture, Japan in 1965. Jpn. J. Sanit. Zool., 18: 218-239. (in Japanese with English summary)

Kim, K. S., Tsuda, Y., Sasaki, T., Kobayashi, M. and Hirota, Y. 2009a. Mosquito blood meal analysis for avian malaria study in wild bird communities: laboratory verification and application to Culex sasai (Diptera: Culicidae) collected in Tokyo, Japan. Parasit. Res., 105: 1351-1357.

Kim, K. S., Tsuda, Y. and Yamada, A. 2009b. Blood-meal identification and detection of avian malaria parasite from mosquitoes (Diptera: Culicidae) inhabiting coastal areas of Tokyo Bay, Japan. J. Med. Entomol., 46: 1230-1234.

Makiya, K. and Sakurai, H. 1975. Survival of the overwintering house mosquito, Culex pipiens pallens, with special reference to the relation between wing length and survival rate. Jpn. J. Sanit. Zool., 26: 7-14.

Mizuta, H., Matsumoto, A., Goto, K. and Kotake, K. 1999. Investigation of mosquito breeding at Kansai International Airport, with special reference to Culex inatomii Kamimura and Wada. Med. Entomol. Zool., 50: 161-164. (in Japanese with English abstract)

Mizuta, H., Ueda, Y., Wakumoto, Y., Haseyama, M., Mori, H., Shiraishi, S. and Goto, I. 2012. Distribution of Culex inatomii (Diptera: Culicidae) in Japan based on results of mosquito surveillances by Quarantine Stations. Med. Entomol. Zool., 63: 11-17

Pradel, J. A., Martin, T., Rey, D., Foussadier, R. and Bicout, D. J. 2009. Is Culex modestus (Diptera: Culicidae), vector of West Nile virus, spreading in the Dombes area, France? J. Med. Entomol., 46: 1269-1281.

Ree, H. I. 1998. Occurrance of Culex (Barraudius) inatomii Kamimura and Wada (Diptera: Clicidae) in a large marsh adjacent to the coast of Ulsan, Korea. J. Am. Mosq. Control Assoc., 14: 344-345.

Shimogama, M. and Takatsuki, Y.. 1967. Seasonal changes in the distribution and abundance of mosquitoes especially of Culex pipiens pallens in a cave in Nagasaki 
City. Endem. Dis. Bull. Nagasaki Univ., 4: 159-165. (In Japanese with English summary)

Tanaka, K. 2005. Culicidae. In: Aquatic Insects of Japan: Manual with Keys and Illustrations, (ed. Kawai, T. and Tanida, K.), pp. 757-1005, Tokai University Press, Hadano-shi.

Tanaka, K., Mizusawa, K. and Saugstad, E. S. 1979. A revision of the adult and larval mosquitoes of Japan (including the Ryukyu Archipelago and the Ogasawara Islands) and Korea (Diptera: Culicidae). Contr. Am. Entomol. Inst., 16: 1-987.

Tsuda, Y. and Kim, K. S. 2010. Prediapause migration and overwintering of Culex tritaeniorhynchus (Diptera:
Culicidae) observed in a park in urban Tokyo during 2007 and 2009. Med. Entomol. Zool., 61: 69-78.

Tsuda, Y., Sasaki, E., Sato, Y., Katano, R., Komagata, O., Isawa, H., Kasai, S. and Murata, K. 2009. Results of mosquito collection from coastal areas of Tokyo Bay receiving migratory birds. Med. Entomol. Zool., 60: 119-124.

Xu, J. J., Yu, Y., Wang, S. P. and Ni, Z. G.. 1993. Occurrence of Culex modestus inatomii Kamimura and Wada in Rongcheng city, Shandong Province. Zhongguo ji sheng chong xue yu ji sheng chong bing za zhi, 11: 5759 . 